\title{
Audits related to safety management systems: Italian case studies
}

\author{
A. Romano, G. Pinetti \& F. Perrone \\ TRR S.r.l., Osio Sotto (BG), Italy
}

\begin{abstract}
The European Directive 96/82/CE and the recent Directive 2003/105/CE [1] report that a Safety Management System must be applied for industrial activities called "Seveso activities"; this is due to the amount of quantities of dangerous substances that can generate major accident risks. The purpose of this paper is to show how audits related to Safety Management Systems are carried out in Italy in recent years, by considering the experience of TRR Company in supporting activities for Seveso industries. Different type of industries will be presented: refineries, chemical plants, steel mills, etc.

Several topics will be discussed, by starting from the operating analysis of accidents occurred in the examined Seveso industry, by analysing the impact of the operating analysis on accidental scenarios included in the Safety Report and, in general terms, the impact on risk analysis. Other topics discussed will be the definition of the critical items that can generate accidental scenarios and the prevention measures adopted to reduce the probability of failure of these items.

The analysis related to the management and design precautions, the mitigation measures and the monitoring instruments for each accidental scenario included in the Safety Report will be presented for identifying the critical points of the Safety Management System and the correct item for the improvement.

Different Italian case studies will be presented in order to show the different approach that can be used for assessing a complex Seveso industry than a simple Seveso industry. A critical analysis will be carried out by using all the elements collected by audits in several Seveso industries for defining the main parameters, in terms of safety indicators, useful to monitor and manage the safety of the industrial activities.
\end{abstract}

Keywords: safety management system, audit, Seveso. 


\section{Introduction}

The Safety Management System should include the part of the general management system which involves the organizational structure, responsibilities, practices, procedures, processes and resources for determining and implementing the major accident prevention policy.

It is recognised that the safe functioning of a Company depends on its overall management. Within this overall management system, the safe operation of a Company requires the implementation of a system of structures, responsibilities, and procedures, with the appropriate resources and technological solutions available. This system is known as the Safety Management System (SMS).

Thus any safety management system is a constituent part of the overall management system of the Company, which may in turn be dependent on a management system developed for a larger entity such as a company or group of companies. The Safety Management System may also involve integration with a management system which addresses other matters, such as the health of workers, the environment, quality, etc. It is possible to develop a safety management system by extending the scope of an existing management system, but it will be incumbent upon the operator to ensure, and demonstrate where necessary, that the management system has been fully developed to cover majoraccident controls and meets the requirements of the Directive.

A further issue in the management system concerns the question "what is management?" While there are different terminologies and detailed definitions, it is accepted now that management of any sizeable activity is based on the idea of a "management loop", which involves agreeing an objective, defining a plan to achieve that objective, formulating the detailed work required to implement the plan, carrying out the work, checking the outcome against the plan, and planning and taking appropriate corrective action. Safety management is no exception to this general principle.

This means that in addition to the goals of the Safety Management System, and the issues it addresses, the integrity of the management loop and the completeness and accurate functioning of the management system are essential.

\section{Elements of safety management systems}

\subsection{Development of a major accident prevention policy (MAPP)}

The Company must draw up a document setting out his Major-Accident Prevention Policy (MAPP) [2]. The document is intended to give an overview of how the Company ensures a high level of protection for man and the environment. The document should take account of the principles contained in Annex III of the SEVESO II Directive in the following seven areas:

- $\quad$ organisation and personnel

- $\quad$ identification and evaluation of major hazards

- operational control 
- management of change

- $\quad$ planning for emergencies

- monitoring performance

- $\quad$ audit and review.

\subsection{Organisation and personnel}

The Safety Management System should reflect the top-down commitment and the safety culture of the Company's organisation, translated into the necessary resources and direct responsibilities of personnel involved in the management of major hazards at all levels in the organisation. The Company should identify the skills and abilities needed by such personnel, and ensure their provision. The role, responsibility, accountability, authority and interrelation of all personnel who manage, perform or verify work affecting safety should be defined, particularly for staff responsible for:

- the provision of resources, including human resources, for SMS development and implementation;

- action to ensure staff awareness of hazards, and compliance with the operator's safety policy;

- identification, recording and follow-up of corrective or improvement actions;

- control of abnormal situations, including emergencies;

- identifying training needs, provision of training, and evaluation of its effectiveness;

- coordinating the implementation of the system and reporting to top management.

\subsection{Hazard identification and evaluation}

The Company should develop and implement procedures to systematically identify and evaluate hazards arising from its activities, and from the substances and materials handled or produced in them. The procedures used for the identification and evaluation of hazards should be formal, systematic, and critical.

There should also be systematic procedures for the definition of measures both for the prevention of incidents and for the mitigation of their consequences. The 'management system' should include an assessment of the skills and knowledge required, including where appropriate a team approach in order to find the necessary combination and range of theoretical and practical knowledge to develop and implement appropriate procedures.

Hazard identification and evaluation procedures should be applied to all relevant stages from project conception through to decommissioning, including:

- potential hazards arising from or identified in the course of planning, design, engineering, construction, commissioning, and development activities; 
- the normal range of process operating conditions, hazards of routine operations and of non-routine situations, in particular start-up, maintenance, and shut-down;

- $\quad$ incidents and possible emergencies, including those arising from component or material failures, external events, and human factors, including failures in the SMS itself;

- $\quad$ hazards of decommissioning, abandonment, and disposal;

- potential hazards from former activities;

- external hazards including those arising from natural hazards (including abnormal temperatures, fire, flood, earthquake, strong winds, tidal waves), from transport operations including loading and unloading, from neighbouring activities, and from malevolent or unauthorised action.

\subsection{Operational control}

The Company should prepare and keep up to date and readily available the information on process hazards and design and operational limits and controls coming from the hazard identification and risk evaluation procedures. Based on these, documented procedures should be prepared and implemented to ensure safe design and operation of plant, processes, equipment and storage facilities. In particular, these procedures should cover:

- Commissioning

- $\quad$ start-up and normal periodic shutdown

- all phases of normal operations, including test, maintenance and inspection

- detection of and response to departures from normal operating conditions

- $\quad$ temporary or special operations

- $\quad$ operation under maintenance conditions

- emergency operations

- decommissioning.

\subsection{Management of change}

The Company should adopt and implement management procedures for planning and controlling all changes in people, plant, processes and process variables, materials, equipment, procedures, software, design or external circumstances which are capable of affecting the control of major accident hazards.

This approach should cover permanent, temporary and urgent operational changes, and should address:

- definition of what constitutes a change

- $\quad$ assignment of responsibilities and authorities for initiating change

- identification and documentation of the change proposed and of its implementation; 
- identification and analysis where appropriate of any safety implications of the change proposed;

- definition, explanation where appropriate, documentation, and implementation of the safety measures deemed appropriate, including information and training requirements, as well as the necessary changes to operational procedures;

- definition and implementation of appropriate post-change review procedures and corrective mechanisms, and subsequent monitoring.

Management of change procedures must also be applied during the design and construction of new installations, processes, and storage facilities.

\subsection{Planning for emergencies}

The Safety Management System includes the procedures necessary to ensure that an adequate emergency plan is developed, adopted, implemented, reviewed, tested, and where necessary revised and updated. These procedures will define the skills and abilities required, including where appropriate a team approach in order to find the necessary combination of theoretical and practical knowledge.

The Company should develop and maintain procedures to identify, by systematic analysis starting from the hazard identification process, foreseeable emergencies arising from or in connection with its activities, and to record and keep up to date the results of this analysis.

Plans to respond to such potential emergencies should be prepared, and arrangements for testing and review on a regular basis should be included within the Safety Management System. The procedures should also cover the necessary arrangements for communication of the plans to all those likely to be affected by an emergency

\subsection{Monitoring performance}

The Company should maintain procedures to ensure that safety performance can be monitored and compared with the safety objectives defined. This should include determining whether plans and objectives are being achieved, and whether arrangements to control risks are being implemented before an incident or accident occurs (active monitoring), as well as the reporting and investigation of failures which have resulted in incidents or accidents (reactive monitoring).

Active monitoring should include inspections of safety critical plant, equipment and instrumentation as well as assessment of compliance with training, instructions and safe working practices. Reactive monitoring requires an effective system for reporting incidents and accidents and an investigation system which identifies not only the immediate causes but also any underlying failures which led to the event. It should pay particular attention to cases of failure of protective measures (including operational and management failures), and should include investigation, analysis, and follow-up (including transfer of information to personnel involved) to ensure that the lessons learnt are applied to future operation. 


\subsection{Audit and review}

In addition to the routine monitoring of performance, the Company should carry out periodic audits of its SMS as a normal part of its business activities. An audit should determine whether the overall performance of the Safety Management System conforms to requirements, both external and those of the operator. The results of these audits should be used to decide what improvements should be made to the elements of the SMS and their implementation. For this purpose the operator should adopt and implement an audit plan covering items previously mentioned.

Senior management should, at appropriate intervals, review the operator's overall safety policy and strategy for the control of major-accident hazards, and all aspects of the SMS to ensure its consistency with these. This review should also address the allocation of resources for SMS implementation, and should consider changes in the organisation as well as those in technology, standards, and legislation [3].

\section{Italian case studies}

By considering audits of Safety Managments System carried out by Italian Authorities for several italian Companies, the following items can be discussed and hightlighted:

- analysis of accidents, incidents and near miss occurred in the examined Company

- analysis of precaution measures (plant and managerial measures) for preventing the occurrence of accidental scenarios

- analysis of critical instrumentation that can directly affects the safety of a plant or unit

- $\quad$ analysis of differences between Hazop carried out for design purposes and Hazop carried out for Safety purposes

- $\quad$ analysis of implementation of Permit to Work System

- $\quad$ analysis of criteria of choice present in the procedures

- $\quad$ analysis of content of the Standard Operating Procedures.

\subsection{Analysis of accidents, incidents and near miss occurred in the examined company}

The Italian Country has issued dedicated guidelines for carrying out audits of Safety Management Systems. The recent guideline is dated April 2008. This guideline identifies a table (Annex 2 of the guideline) as an instrument for collecting accidents, incident or near miss occurred in the Company.

By considering TRR experience in Safety Management System audits, the main critical items discovered in this type of topic are: 
- difficulties in obtaining data and in case of presence of data, no statistical analysis was carried out, in terms of type of item involved, causes, consequences

- presence of accidents with the same cause (occurring several times in the years) and related accidental scenarios not included in the risk analysis of the Safety Report.

\subsection{Analysis of prevention and control measures (plant and managerial measures) for preventing the occurrence of accidental scenarios}

By considering the guideline mentioned before, the attachment 4 is dedicated for including all prevention and control measures related to each accidental scenario that can occur in the Company. In this analysis all accidental hypothesis have to be considered (credible and not credible).

In particular the items to be included in the analysis are the following:

- $\quad$ accidental hypothesis identified in the Safety Report;

- $\quad$ type of plant protection present (alarms, interlock systems, etc.)

- type of managerial protection present (procedures, permit to work systems, etc)

- actions to be taken in case of accident occurrence (fire fighting, depressurization procedures, etc)

- $\quad$ instrument for the event monitoring (camera system, gas detection, etc.).

By considering TRR experience in Safety Management System audits, the main critical items discovered in this type of topic are:

- absence in some cases of prevention measures in several accidental scenarios

- $\quad$ absence in some cases of instruments for reconstructing the event after the accident in order to carry out an investigation analysis.

\subsection{Analysis of critical instrumentation that can directly affects the safety of a plant or unit}

The critical instrumentation as pressure safety valves, interlock systems, etc has a key role in the prevention of the accidental scenarios. The Safety Management System has to control the presence, maintenance and the reliability of these items.

By considering TRR experience in Safety Management System audits, the main critical items discovered in this type of topic are:

- $\quad$ in some cases instrumentation considered critical in the Safety Report for preventing the accidental scenarios, but wasn't included in the list of critical instrumentation of the Safety Management System

- discordance in some cases between test frequency of the critical instrumentation identified in the Safety Report (Fault Tree Analysis) and the real test frequency carried out by the Maintenance Department. 


\subsection{Analysis of differences between Hazop carried out for design purposes and Hazop carried out for safety purposes}

The Safety Management System has a key role in the definition of the accidental scenarios and the related prevention. A risk analysis technique used for the definition of accidental hypothesis is Hazop (Hazard \& Operability Analysis).

Hazop can have several purposes. In case of design of a new unit or plant a Hazop for controlling the rating of piping, the design conditions of process vessels, etc is carried out.

There is an other type of Hazop carried out for safety purposes and not for only operational purposes.

This type of Hazop defines if protection measures are enough in case of an examined deviation (pressure, temperature, flow, etc.) and it is necessary for fault tree analysis and consequent accidental scenarios identification.

By considering TRR experience in Safety Management System audits, the main critical items discovered in this type of topic are:

- $\quad$ the presence in the Company of a Hazop with different purposes (design and process and not for safety)

- the up-dating process of Hazop analysis is not carried out during the time, in case of modifications of units, in order to define if that modification or change can negatively involve other units of the Company in term of Safety.

\subsection{Analysis of implementation of permit to work system}

The Permit to Work System is an instrument for carrying out maintenance activities, operations activities and construction activities in a safe manner. This instrument requires several certifications in case of electric works or process vessel isolation.

The Permit to Work System requires also several signatures, as:

- $\quad$ representative of the Company that carries out the job

- $\quad$ representative of the Company that checks the job carried out

- $\quad$ representative of the Company that defines the safety criteria for carrying out the job

- representative of the Company that manages the area where the job is carried out.

- $\quad$ By considering TRR experience in Safety Management System audits, the main critical items discovered in this type of topic are:

- $\quad$ in some cases Permit to Work System was implemented only for jobs out sourced

- $\quad$ in some cases missed control of the job in term of safety aspects during the intervention. 


\subsection{Analysis of criteria of choice present in the procedures}

The Procedures represent the core of the Safety Management System. The procedures can be operating or managerial. The common element of the two type of procedures are the choice criteria.

The choice criteria are important due to the possibility to carry out an activity (investigation, training, maintenance, etc.) in a standardized manner and each figure that has to carry out that activity shall follow dedicated steps.

By considering TRR experience in Safety Management System audits, the main critical items discovered in this type of topic is in some cases the absence of choice criteria in procedures, for example change procedure or risk analysis procedure, where without identified and consolidated criteria is difficult carry out risk analysis and define priorities.

\subsection{Analysis of content of the standard operating procedures}

Standard Operating procedures define the step to be followed for carrying out an activity in the correct way and in a safe manner. Without Standard Operating Procedures is difficult to implement a system that can allow to maintain a high level of safety and quality.

By considering TRR experience in Safety Management System audits, the main critical items discovered in this type of topic is in some cases the lack of information in Standard Operating Procedures of the following items:

- Hazards related to the examined activity

- $\quad$ personnel protective equipment to be used in order to carry out the activity or the job in a safe manner.

\section{References}

[1] Attuazione della direttiva 2003/105/CE, che modifica la direttiva 96/82/CE, sul controllo dei pericoli di incidenti rilevanti connessi con determinate sostanze pericolose, D.Lgs. 238/05, Italia.

[2] Linee guida per l'attuazione del sistema di gestione della sicurezza, D.M. 09/08/2000, Italia.

[3] Neil Mitchison \& Sam Porter (Eds.), Guidelines on a Major Accident Prevention Policy and Safety Management System, as required by Council Directive 96/82/EC (SEVESO II). 